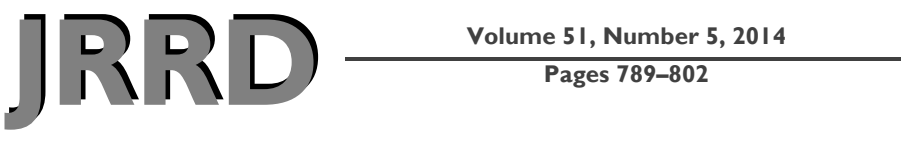

\title{
Pushrim biomechanical changes with progressive increases in slope during motorized treadmill manual wheelchair propulsion in individuals with spinal cord injury
}

\author{
Dany H. Gagnon, PT, PhD; ${ }^{*}$ Annie-Claude Babineau; ${ }^{1}$ Audrey Champagne; ${ }^{1}$ Guillaume Desroches, PhD; ${ }^{1}$ \\ Rachid Aissaoui, Eng PhD $^{2}$ \\ ${ }^{1}$ School of Rehabilitation, Université de Montréal, Montreal, Canada; and Pathokinesiology Laboratory, Centre for \\ Interdisciplinary Research in Rehabilitation of Greater Montreal, Institut de Réadaptation Gingras-Lindsay-de-Montréal, \\ Montreal, Canada; ${ }^{2}$ Department of Automated Production Engineering, École de Technologie Supérieure, Montreal, \\ Canada
}

\begin{abstract}
The purpose of this study was to quantify the effects of five distinct slopes on spatiotemporal and pushrim kinetic measures at the nondominant upper limb during manual wheelchair (MWC) propulsion on a motorized treadmill in individuals with spinal cord injury (SCI). Eighteen participants with SCI propelled their MWC at a self-selected natural speed on a treadmill at different slopes (0, 2.7, 3.6, 4.8, and 7.1 degrees). Spatiotemporal parameters along with total force and tangential components of the force applied to the pushrim, including mechanical effective force, were calculated using an instrumented wheel. The duration of the recovery phase was $54 \%$ to $70 \%$ faster as the slope increased, whereas the duration of the push phase remained similar. The initial contact angles migrated forward on the pushrim, while the final and total contact angles remained similar as the slope increased. As the slope increased, the mean total force was $93 \%$ to $201 \%$ higher and the mean tangential component of the force was $96 \%$ to $176 \%$ higher than propulsion with no slope. Measures were similar for the 2.7 and 3.6 degrees slopes. Overall, the recovery phase became shorter and the forces applied at the pushrim became greater as the slope of the treadmill increased during motorized treadmill MWC propulsion.
\end{abstract}

Key words: biomechanics, exercise test, paraplegia, quadriplegia, ramps, rehabilitation, spinal cord injuries, task performance and analysis, upper limb, wheelchairs.

\section{INTRODUCTION}

The majority of people who sustain a spinal cord injury (SCI) will not regain the necessary sensorimotor capabilities to walk independently or efficiently and must consequently learn to get around in a manual wheelchair (MWC). During the rehabilitation process, they will be encouraged to learn basic and advanced MWC skills so they can optimize their level of independence during

Abbreviations: AIS = American Spinal Injury Association Impairment Scale, CIHR = Canadian Institutes of Health Research, FRQS = Fonds de la Recherche du Québec-Santé, $\mathrm{F}_{\mathrm{TANG}}=$ tangential component of force, $\mathrm{F}_{\mathrm{TOT}}=$ total force, $\mathrm{MEF}=$ mechanical effective force, $\mathrm{MWC}=$ manual wheelchair, $\mathrm{MWU}=$ manual wheelchair user, REPAR = Quebec Rehabilitation Research Network, SCI = spinal cord injury, $\mathrm{UL}=$ upper limb.

*Address all correspondence to Dany H. Gagnon, PT, PhD; Pathokinesiology Laboratory, Centre for Interdisciplinary Research in Rehabilitation of Greater Montreal, Institut de Réadaptation Gingras-Lindsay-de-Montréal, 6300 Darlington, Montreal, QC, Canada H3S 2J4; 514-343-6111, ext 26382; fax: 514-340-2154.

Email: dany.gagnon.2@umontreal.ca

http://dx.doi.org/10.1682/JRRD.2013.07.0168 
MWC propulsion and MWC-related functional activities performed in their natural environment. For example, they will often have to negotiate slopes of different lengths and angles. For MWC users (MWUs), slopes are not just an environmental or architectural challenge to overcome, but they also represent a way to access many public and private spaces or buildings, which facilitates their social integration and participation [1]. According to various recommendations and standards in Canada and the United States [2-4], access ramps can have different slopes, ranging from 1 unit of height to 12, 16, or 20 units of length for ramps less than $9 \mathrm{~m}$ long in new buildings or 8 or 10 units of length for ramps less than $3 \mathrm{~m}$ long or for vertical rises less than $15 \mathrm{~cm}$ in existing buildings or confined spaces. Under no circumstance are slopes steeper than 1:8 permitted by these recommendations and standards. However, in reality, slopes are sometimes steeper because of space limitations (e.g., private residential property) or the inherent inability to modify the natural environment. Consequently, it is relevant to gain additional insight on the specificities of these different slopes during MWC propulsion.

To date, only a few studies have investigated upperlimb (UL) efforts during uphill propulsion among MWUs. In a study done with 20 MWUs with various diagnoses, Sanford et al. reported that, for a $9 \mathrm{~m}$-long adjustable slope, 85 percent of the participants could climb a slope of 1:12, 80 percent successfully negotiated a 1:10 slope, and only 75 percent managed to ascend a 1:8 slope while propelling their own MWC at a selfselected natural speed [5]. Moreover, other studies confirmed that a substantial number of MWUs are unable to climb steeper slopes: Templer et al. reported that only 80 percent of MWUs could manage a slope gradient of 1:10 [6], Sweeney et al. mentioned that 88 percent of their participants were able to climb $1: 12$ to $1: 7$ slopes [7], and Steinfield et al. documented that approximately 50 percent of MWUs tested could propel the full length of a 1:12 ramp measuring approximately $40 \mathrm{~m}$ in length [8]. To date, no study has investigated whether these success rates measured during uphill propulsion in a simulated natural environment are comparable with those reached during treadmill propulsion among MWUs.

In addition to the UL efforts routinely generated by MWUs during propulsion and other functional activities (e.g., transfers, pressure-relief lifts, loading the MWC in a car), propelling uphill puts additional demand on the MWU's ULs, which further increases the risk of second- ary musculoskeletal impairments, especially at the wrists and shoulders [9-10]. In fact, Arabi et al. calculated among nondisabled subjects that 46 percent of the maximal isometric propulsive force generated is necessary to move an MWC up a slope of 1:20 and 61 percent for a slope of 1:10 when propelling on a dynamometer [11]. Richter et al. found that among a large group of MWUs with SCI, propelling at a self-selected velocity on a motorized treadmill, the speed was about 1.5 and 2.7 times slower when pushing up $3^{\circ}$ and $6^{\circ}$ slopes, respectively, in comparison with the level surface $\left(0^{\circ}\right.$ slope) [12]. Additionally, Richter et al. also documented that the peak total force $\left(\mathrm{F}_{\mathrm{TOT}}\right)$ was about 1.7 and 2.2 times slower when pushing up $3^{\circ}$ and $6^{\circ}$ slopes, respectively, in comparison with the level surface $\left(0^{\circ}\right.$ slope) despite the reduced treadmill speed [12]. More recently, Yang et al. found that among a group of MWUs with SCI, propelling at a steady speed of $0.9 \mathrm{~m} / \mathrm{s}$ on a motorized treadmill, the $\mathrm{F}_{\text {TOT }}$ and tangential components of the force ( $\mathrm{F}_{\text {TANG }}$ ) applied at the handrim were about 2.1 and 2.4 times higher when pushing up a $3^{\circ}$ slope (approximately 1:20 ratio) in comparison with the level surface, whereas the mechanical efficiency was only found to be 1.1 times higher [13]. Such differences confirm the need to gain a better understanding of the effects of steeper slopes on spatiotemporal and pushrim kinetic parameters during uphill propulsion on a treadmill set at a steady speed.

There has been a growing interest for motorized treadmill propulsion in the recent year in rehabilitation research and in clinical practice. Motorized treadmill propulsion seems to closely duplicate the conditions usually encountered in the daily lives of MWUs (i.e., external validity), especially since speed and slope parameters are usually modifiable and propulsion over a prolonged period of time in a restricted space becomes possible. Moreover, unlike propulsion on a roller ergometer or a dynamometer, MWC propulsion on a motorized treadmill allows for greater freedom of MWC movement and some exposure to the effects of inertia linked to the acceleration and deceleration of the MWC, head-trunk-UL segments, and air resistance [14]. Surprisingly, unlike walking, only a few studies on MWC propulsion have been done on an incline [1,15-17], fewer have been done on a motorized treadmill [12-13,18-21], and none have assessed the effects of more than one slope (i.e., incline) while propelling at a steady speed on a motorized treadmill.

The main objective of this study was to quantify the effects of five different slopes $\left(0^{\circ}, 2.7^{\circ}, 3.6^{\circ}, 4.8^{\circ}\right.$, and 
$7.1^{\circ}$ from the ground) on the spatiotemporal propulsion cycle and pushrim kinetic measures of the nondominant UL during MWC propulsion at self-selected natural speeds on a motorized treadmill in a laboratory setting (i.e., simulated environment). It was expected that the duration of the recovery phase would significantly decrease, the $\mathrm{F}_{\text {TOT }}$ and $\mathrm{F}_{\text {TANG }}$ applied at the pushrim would significantly increase, and the mechanical effective force (MEF) would remain comparable with each increase in the angle from the ground (i.e., slope).

\section{METHODS}

\section{Selection and Description of Participants}

A convenience sample of 18 adults (17 male and 1 female) volunteered to participate in this study after responding to advertisements posted within the rehabilitation facility and on the Web site of the pathokinesiology laboratory, to recruitment letters sent directly to them, or to telephone invitations for participants who had given their consent to be contacted directly within a $5 \mathrm{yr}$ period following participation in a previous project conducted by the same research team (Table 1). To be included in the study, participants had to have sustained a complete or incomplete SCI (American Spinal Injury Association Impairment Scale [AIS] A, B, C, or D [22]) at least 3 mo before the study; have been discharged from initial intensive inpatient rehabilitation services; use their MWC for more than $4 \mathrm{~h} / \mathrm{d}$; and be independent in their MWC mobility in the community, including climbing an access ramp that met building code standards in the province of Quebec in Canada (i.e., maximum slope ratio $=1$ unit of height by 12 units of length for slopes of a maximum length of $9 \mathrm{~m}$ ) [3]. This standard is similar to the one recommended in the Americans With Disabilities Act [4]. Participants were excluded from this study if they presented other neurological conditions or UL musculoskeletal impairments and/or pain, cardiorespiratory and/or vascular conditions, or any other impairments or disabilities that might have interfered with the performance or the

Table 1.

Description of participants.

\begin{tabular}{|c|c|c|c|c|c|c|c|c|c|c|c|c|}
\hline \multirow[b]{2}{*}{ Subject } & \multirow[b]{2}{*}{ Sex } & \multirow{2}{*}{$\begin{array}{l}\text { Age } \\
\text { (yr) }\end{array}$} & \multirow{2}{*}{$\begin{array}{c}\text { Height } \\
\text { (m) }\end{array}$} & \multirow{2}{*}{$\begin{array}{c}\text { Weight } \\
\text { (kg) }\end{array}$} & \multirow{2}{*}{$\begin{array}{l}\text { Time Since } \\
\text { Injury (yr) }\end{array}$} & \multicolumn{4}{|c|}{ ASIA } & \multicolumn{3}{|c|}{ WUSPI } \\
\hline & & & & & & $\begin{array}{c}\text { Neurological } \\
\text { Level }\end{array}$ & AIS* & $\begin{array}{l}\text { Sensory } \\
(/ 224)\end{array}$ & $\begin{array}{l}\text { Motor } \\
(/ 100)\end{array}$ & $\begin{array}{l}\text { Mean } \\
(/ 10)\end{array}$ & $\begin{array}{c}\text { Propulsion } \\
10 \min (/ 10)\end{array}$ & $\begin{array}{l}\text { Slope } \\
(/ 10)\end{array}$ \\
\hline 1 & $\mathrm{M}$ & 44.3 & 1.84 & 80.3 & 10.6 & $\mathrm{~T} 7$ & $\mathrm{~A}$ & 117 & 50 & 0.19 & 0.0 & 0.0 \\
\hline 2 & M & 46.4 & 1.70 & 80.2 & 4.6 & T10 & B & 140 & 50 & 0.68 & 0.1 & 0.5 \\
\hline 3 & M & 32.2 & 1.92 & 95.9 & 5.3 & T10 & A & 140 & 50 & 0.00 & 0.0 & 0.0 \\
\hline 4 & M & 35.8 & 1.80 & 77.1 & 11.8 & T6 & $\mathrm{D}$ & 194 & 81 & 1.25 & 1.9 & 2.2 \\
\hline 7 & M & 59.9 & 1.88 & 99.8 & 5.0 & T10 & A & 140 & 50 & 0.34 & 0.4 & 2.2 \\
\hline 8 & M & 44.0 & 1.72 & 68.4 & 22.1 & $\mathrm{~T} 4$ & B & 183 & 35 & 0.07 & 0.9 & 0.0 \\
\hline 9 & M & 41.2 & 1.78 & 72.7 & 6.1 & C7 & C & 56 & 44 & 1.23 & 2.7 & 2.7 \\
\hline 10 & M & 28.4 & 1.85 & 66.6 & 10.6 & T12 & A & 154 & 50 & 0.63 & 3.8 & 1.9 \\
\hline 11 & M & 39.0 & 1.76 & 101.8 & 2.8 & T10 & A & 72 & 50 & 3.65 & 5.5 & 6.8 \\
\hline 15 & F & 28.1 & 1.65 & 47.5 & 4.8 & T11 & A & 148 & 50 & 0.20 & 2.0 & 1.0 \\
\hline 16 & M & 33.0 & 1.65 & 66.5 & 5.3 & T6 & A & 53 & 50 & 0.10 & 0.0 & 0.3 \\
\hline 17 & M & 52.7 & 1.73 & 78.2 & 8.9 & $\mathrm{~T} 12$ & B & 172 & 63 & 3.12 & 2.6 & 4.8 \\
\hline 18 & M & 25.8 & 1.83 & 59.2 & 4.9 & $\mathrm{~T} 7$ & A & 112 & 50 & 1.88 & 4.7 & 2.6 \\
\hline Mean \pm SD & - & $40.8 \pm 10.3$ & $1.78 \pm 0.09$ & $78.7 \pm 17.0$ & $8.2 \pm 5.1$ & - & - & $124.8 \pm 42.3$ & $51.7 \pm 9.0$ & $0.89 \pm 1.05$ & $1.7 \pm 1.7$ & $1.8 \pm 1.9$ \\
\hline
\end{tabular}


safety of the experimental tasks. Potential participants were invited to contact the rehabilitation research coordinator to review the inclusion and exclusion criteria and to determine eligibility during a structured telephone interview before scheduling the clinical and laboratory assessments.

\section{Clinical Assessment}

Before starting the experimental tasks in the laboratory, each participant underwent a clinical assessment completed by a physical therapist. The main objective was to collect the participants' personal characteristics (age, time since injury, MWC experience, etc.), measure anthropometric parameters (height, weight), characterize the severity of the sensory and motor impairments (AIS [22]), confirm that no incapacitating musculoskeletal impairment affected their ULs (i.e., Wheelchair User's Shoulder Pain Index [23-24], UL joint ranges of motion, UL static manual muscle testing), and determine UL nondominance [25].

\section{Laboratory Assessment}

\section{Experimental Tasks}

To determine their self-selected natural MWC propulsion speed, participants did the MWC propulsion test over a distance of $20 \mathrm{~m}$ in a corridor (tiled surface). The test performed at the natural self-selected speed was timed: the stopwatch was clicked on when participants started to propel (with their front wheels at the start line) and clicked off when the front wheels crossed the finish line. Three trials were conducted unless there was a variation of more than 10 percent, in which case a fourth trial was done. A 2 min rest was taken between each test. The mean time (in seconds) of the three tests was used to select the speed of the treadmill corresponding with the selfselected natural MWC propulsion speed on the ground.

Participants propelled their MWC on a dual-belt instrumented treadmill (width $=0.84 \mathrm{~m}$; length $=1.84 \mathrm{~m}$ ) specially adapted for MWC propulsion (Bertec Corporation; Columbus, Ohio). The treadmill was also equipped with a bilateral frictionless gliding safety system that limits the anteroposterior and rotational movements of the MWC, given that the MWC is anchored to it with elastic bands (Figure 1(a)). Prior to carrying out the experimental tasks, participants completed a familiarization period to become accustomed to propulsion on the treadmill at different speeds and slopes from those studied. For the
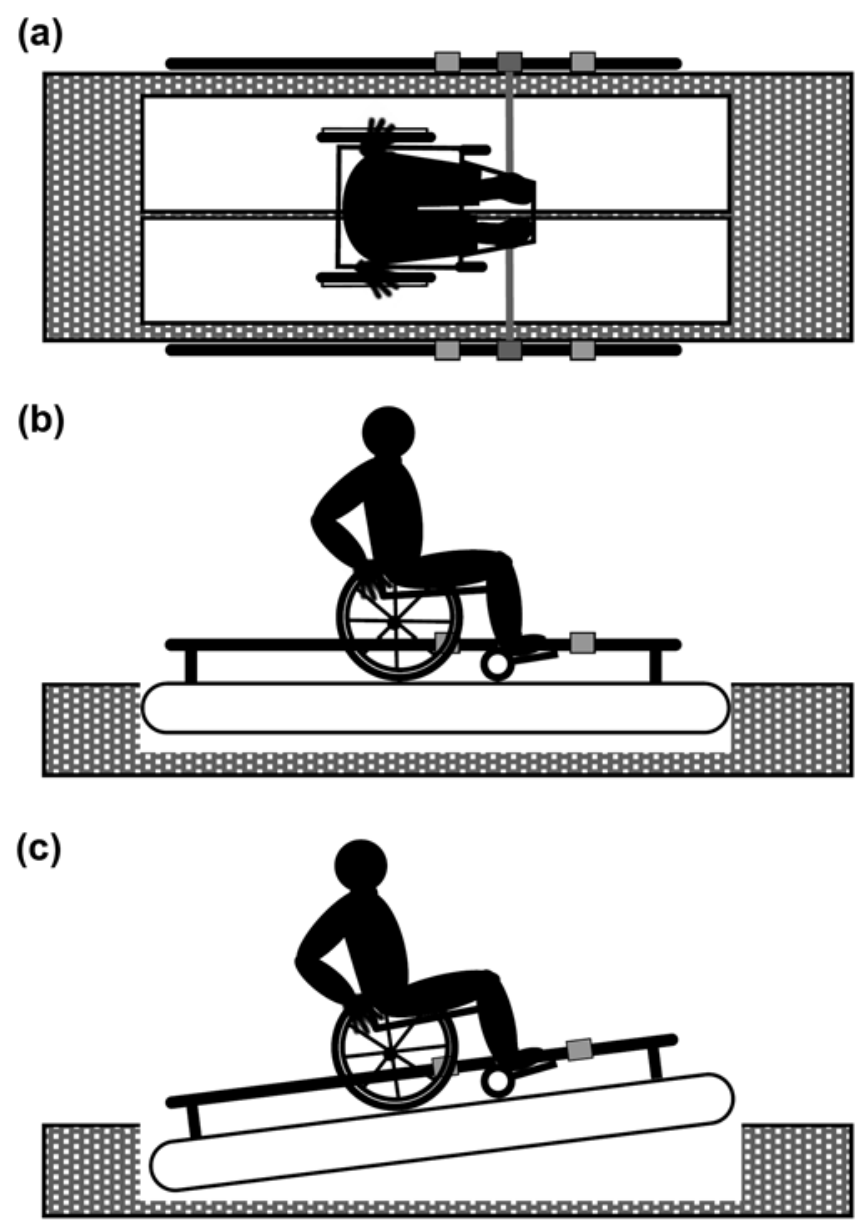

Figure 1.

Schematic representation of laboratory setup using (a) superior view and lateral view at (b) $0^{\circ}$ and (c) with slope.

experimental tasks, each participant completed two trials lasting a maximum of $1 \mathrm{~min}$ at the self-selected natural speed measured on the ground for each of five treadmill slopes: $0^{\circ}, 2.7^{\circ}, 3.6^{\circ}, 4.8^{\circ}$, and $7.1^{\circ}$ (Figure 1). The four slopes greater than $0^{\circ}$ corresponded with slopes that increase from 1 unit of height to 20,16,12, and 8 units of length, respectively. The order in which the tasks were done was randomly determined a priori, except for the task at $0^{\circ}$, which was always done first, given some methodological limitations (e.g., laboratory calibration). A 2 min rest was taken between each trial. At the end of each trial, participants rated their perceived effort exerted at the nondominant UL (i.e., peripheral exertion) using a $10 \mathrm{~cm}$-horizontal visual analog scale ranging from 0 (no effort) to 10 (maximum effort) without seeing their previous ratings. 


\section{Kinetics-Instrumented Wheels}

The participants' MWCs were equipped bilaterally with instrumented wheels (SMARTWheel; Londonderry, New Hampshire) to measure pushrim forces and moments at a sampling frequency of $240 \mathrm{~Hz}$ [26]. Once installed on the participant's MWC, aside from the increased width and weight of the MWC (4.8 kg/instrumented wheel) that effects the inertial and rolling resistance properties, the instrumented wheels did not alter axle position and other rear wheel characteristics (e.g., orientation and diameter of the pushrims). We opted to install 24 or 26 in. SMARTWheels bilaterally, even though only the data at the nondominant ULs were analyzed, in order to not generate a rotational torque around participants' MWC on the slopes. The recorded pushrim forces and moments were sent in real time by telemetry to a computer and continuously recorded with the SMARTWheel software program. Data from the SMARTWheel were filtered with a fourth-order Butterworth filter and a cut-off frequency of $20 \mathrm{~Hz}$ [27] using an in-house MATLAB routine (The MathWorks Inc; Natick, Massachusetts). Only the data at the nondominant UL were analyzed because it is expected that the nondominant UL, which may have the lowest force generating capability, may limit performance during a functional task requiring symmetrical bilateral efforts such as propelling a MWC on a linear trajectory [28].

\section{Main Outcome Measures}

\section{Manual Wheelchair Propulsion Phases}

To facilitate data analysis, MWC propulsion was divided into two distinct phases: the push phase and the recovery phase. The push phase was when the hand grips the rim and was determined by the presence of force on the pushrim (threshold $=\mathrm{F}_{\mathrm{TOT}}>3 \%$ of maximum [in newtons] [27]). The recovery phase was when the hand was not in contact with the rim, and it was determined by the absence of force on the rim. The propulsion cycle was the combination of the push and recovery phases. The mean duration of the propulsion cycle and the specific mean durations of the push and recovery phases were calculated. Since forces could be recorded only during the push phase, only the pushrim kinetic data collected during this phase were analyzed and normalized to 100 percent (100 data points). Note that the last 20 consecutive propulsion cycles recorded during each trial were used to obtain mean values of the measures of interest for each trial and were essential to confirm successful completion for each slope (i.e., two trials/slope).

\section{Contact Angle of Hand with Pushrim}

The contact angle of the nondominant hand with the pushrim was calculated from the hand's center of mass in relation to the rear-wheel radius, with respect to a vertical axis used as a reference [29]. The contact angle is the difference calculated between the initial and the final position of the nondominant hand on the MWC pushrim. For each of these three variables (initial position, final position, and contact angle), a group mean was calculated and reported.

\section{Pushrim Kinetics}

The instrumented wheels enabled us to calculate the $\mathrm{F}_{\mathrm{TOT}}$, which is the vectorial sum of the individual forces $\left(\mathrm{F}_{x}, \mathrm{~F}_{y}\right.$, and $\left.\mathrm{F}_{z}\right)$ applied to the pushrim, and the $\mathrm{F}_{\text {TANG }}$ which contributes directly to the forward or backward displacement of the MWC. The $\mathrm{F}_{\text {TANG }}$ was measured using the method proposed by Cooper et al., which first determines the point of force application on the wheel from the hand kinematic data, then uses an equation to calculate the $\mathrm{F}_{\text {TANG }}$ [30]. The hand kinetic data was computed using three light-emitting diodes fixed to the nondominant hand segment and recorded with an Optotrak motion analysis system (NDI; Waterloo, Canada) (sampling frequency $=60 \mathrm{~Hz}$ ) [31]. The MEF, which is the proportion of the force applied to the pushrim that contributes directly to the forward rotation of the wheel expressed as a percentage, was calculated. The MEF is defined by $\left(\mathrm{F}_{\mathrm{TANG}}{ }^{2} / \mathrm{F}_{\mathrm{TOT}}{ }^{2}\right) \times 100$ as proposed by Cooper et al. [30]. These main outcome measures were selected because they may be related to the development of secondary musculoskeletal impairments in MWUs' ULs [32]. The mean profiles of each of these variables $\left(\mathrm{F}_{\mathrm{TOT}}\right.$, $\mathrm{F}_{\mathrm{TANG}}$, and MEF) were presented as curves on a graph, with means and maxima, to compare the efforts between the different slopes.

\section{Statistical Analyses}

The mean \pm standard deviation of the group of participants was calculated for the demographic and clinical data (Table 1) and for all the main outcome measures (Table 2). For each of these measures, 10 propulsion cycles were averaged per trial (total $=20$ propulsion cycles per experimental condition). To confirm the normality of the data distribution, the Kolmogorov-Smirnov 
JRRD, Volume 51, Number 5, 2014

Table 2.

Summary of main outcome measures for each slope (mean \pm standard deviation) with percentage comparison to $0^{\circ}$.

\begin{tabular}{|c|c|c|c|c|c|}
\hline \multirow{2}{*}{ Main Outcome Measures } & \multicolumn{5}{|c|}{ Motorized Treadmill Slope } \\
\hline & $\mathbf{0}^{\circ}$ & $2.7^{\circ}$ & $3.6^{\circ}$ & $4.8^{\circ}$ & $7.1^{\circ}$ \\
\hline \multicolumn{6}{|l|}{ Temporal Parameters (s) } \\
\hline Push Phase & $0.48 \pm 0.08$ & $0.48 \pm 0.08$ & $0.49 \pm 0.08$ & $0.48 \pm 0.07$ & $0.48 \pm 0.06$ \\
\hline Change (\%) & - & 0.81 & 2.41 & 1.91 & 0.86 \\
\hline Recovery Phase & $0.59 \pm 0.22$ & $0.27 \pm 0.10$ & $0.26 \pm 0.09$ & $0.22 \pm 0.08$ & $0.18 \pm 0.05$ \\
\hline Change (\%) & - & -54.15 & -56.16 & -63.24 & -70.33 \\
\hline Total & $1.07 \pm 0.23$ & $0.75 \pm 0.16$ & $0.75 \pm 0.14$ & $0.70 \pm 0.13$ & $0.66 \pm 0.10$ \\
\hline Change (\%) & - & -29.73 & -30.14 & -34.29 & -38.70 \\
\hline \multicolumn{6}{|l|}{ Contact Angle $\left({ }^{\circ}\right)$} \\
\hline Initial & $-33.00 \pm 9.75$ & $-19.84 \pm 12.02$ & $-17.60 \pm 9.70$ & $-11.08 \pm 10.20$ & $0.81 \pm 8.55$ \\
\hline Change (\%) & - & -39.88 & -46.67 & -66.42 & -102.45 \\
\hline Final & $45.97 \pm 9.04$ & $52.04 \pm 9.20$ & $53.46 \pm 10.36$ & $57.92 \pm 11.82$ & $65.54 \pm 9.82$ \\
\hline Change (\%) & - & 13.20 & 16.29 & 26.00 & 42.57 \\
\hline Total & $78.97 \pm 13.27$ & $68.94 \pm 22.92$ & $69.90 \pm 14.77$ & $66.91 \pm 15.36$ & $56.12 \pm 28.17$ \\
\hline Change (\%) & - & -12.71 & -11.48 & -15.27 & -28.93 \\
\hline \multicolumn{6}{|l|}{ Total Force (N) } \\
\hline Mean & $39.56 \pm 11.15$ & $76.25 \pm 19.55$ & $81.49 \pm 18.86$ & $95.49 \pm 21.16$ & $119.21 \pm 18.42$ \\
\hline Change (\%) & - & 92.75 & 105.99 & 141.38 & 201.34 \\
\hline Maximum & $66.2 \pm 21.66$ & $133.28 \pm 47.75$ & $134.97 \pm 29.95$ & $163.76 \pm 40.44$ & $205.06 \pm 28.22$ \\
\hline Change (\%) & - & 101.33 & 103.88 & 147.37 & 209.76 \\
\hline \multicolumn{6}{|l|}{ Tangential Force (N) } \\
\hline Mean & $24.52 \pm 8.84$ & $48.07 \pm 13.08$ & $52.25 \pm 14.27$ & $58.00 \pm 14.69$ & $68.05 \pm 16.61$ \\
\hline Change (\%) & - & 96.04 & 113.09 & 136.54 & 177.53 \\
\hline Maximum & $46.03 \pm 15.56$ & $97.42 \pm 30.86$ & $99.65 \pm 24.83$ & $116.08 \pm 30.78$ & $138.72 \pm 31.43$ \\
\hline Change (\%) & - & 111.64 & 116.49 & 152.18 & 201.37 \\
\hline \multicolumn{6}{|l|}{ Mechanical Effective Force } \\
\hline Mean & $0.43 \pm 0.09$ & $0.44 \pm 0.06$ & $0.45 \pm 0.10$ & $0.42 \pm 0.06$ & $0.38 \pm 0.10$ \\
\hline Change (\%) & - & 2.33 & 4.65 & -2.33 & -11.63 \\
\hline Maximum & $0.75 \pm 0.12$ & $0.80 \pm 0.09$ & $0.80 \pm 0.12$ & $0.77 \pm 0.09$ & $0.76 \pm 0.10$ \\
\hline Change (\%) & - & 6.67 & 6.67 & 2.67 & 1.33 \\
\hline \multicolumn{6}{|l|}{ Perceived Effort (/10) } \\
\hline Mean & $1.18 \pm 1.10$ & $3.78 \pm 2.83$ & $4.06 \pm 2.69$ & $5.27 \pm 2.80$ & $6.86 \pm 2.68$ \\
\hline Change (\%) & - & 219.87 & 243.89 & 346.07 & 480.27 \\
\hline
\end{tabular}

test was applied for a single sample $(p>0.05)$ for all measures at every slope tested. Then, to verify the effects of the increase in treadmill slope on the variables of interest, analyses of variance with a one-factor intrasubject repeated measure (slopes of $0^{\circ}, 2.7^{\circ}, 3.6^{\circ}, 4.8^{\circ}$, and $7.1^{\circ}$ ) were calculated with a significance level set at $p<0.05$. When there were significant differences, Student $t$-tests for paired samples were computed (post hoc tests) with an adjusted significance level set at $p<0.005(p=0.05 /$ 10 possible comparison pairs). Statistical analyses were performed with SPSS version 17.0 (IBM Corporation; Armonk, New York).

\section{RESULTS}

All of the participants were able to propel their MWC on level ground ( $0^{\circ}$ slope) and up a $2.7^{\circ}$ slope (completion rate $=100 \%)$. For the $3.6^{\circ}$ and $4.8^{\circ}$ slopes, the majority of the participants could propel the MWC, with 
completion rates of 88.9 percent ( $n=16 / 18$ participants) and 77.8 percent ( $n=14 / 18$ participants), respectively. Finally, 55.6 percent ( $n=10 / 18$ participants) of the participants successfully propelled their MWC up the $7.1^{\circ}$ slope. The mean self-selected comfortable propulsion speed selected by the participants was $1.17 \pm 0.18 \mathrm{~m} / \mathrm{s}$ ( minimum $=0.91 \mathrm{~m} / \mathrm{s}$, maximum $=1.65 \mathrm{~m} / \mathrm{s}$ ). Table 2 reports a summary of the main outcome measures, and Figures 2, 3, and 4 illustrate these data.

\section{Manual Wheelchair Propulsion Phases}

Figure 2 and Table 2 summarize the mean duration of the push and recovery phases and the total duration of a propulsion cycle (in seconds) for the different treadmill slopes. The average durations of the push phase were similar for each slope $(p=0.27)$. Although the average duration of the recovery phase declined as the treadmill angle increased for the majority of the slopes tested, the differences reported between the $2.7^{\circ}$ and $3.6^{\circ}$ slopes were not significant $(p=0.04)$. The recovery phase at $0^{\circ}$ was generally from 54 to 70 percent $(p<0.001)$ longer than for the different slopes.

\section{Contact Angle of Hand with Pushrim}

Figure 3(a)-(c) and Table 2 summarize the different contact angles calculated for the nondominant side for the different slopes tested on the treadmill. With an increase in treadmill slope from $0^{\circ}$ to $7.1^{\circ}$, the initial (minimum) and final (maximum) contact angles (Figure 3(c)) increased from $-33.00^{\circ} \pm 9.75^{\circ}$ to $0.81^{\circ} \pm 8.55^{\circ}$ and from $45.97^{\circ} \pm 9.04^{\circ}$ to $65.54^{\circ} \pm 9.82^{\circ}$, respectively (mean \pm standard deviation). The initial contact angle

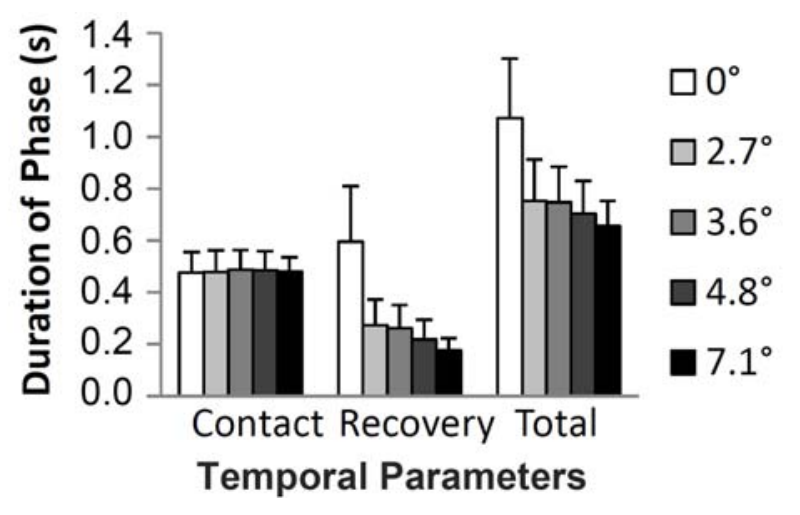

Figure 2.

Group means + standard deviation of temporal parameters for five different slopes at constant speed (mean $=1.17 \pm 0.18 \mathrm{~m} / \mathrm{s}$ ). progressively migrated forward as the slope increased, except that the initial contact angle between the $2.7^{\circ}$ and $3.6^{\circ}$ slopes was found to be similar $(p=0.04)$. The final contact angle was similar across all slopes $(p=0.04$ 0.48 ) except for the $0^{\circ}$ slope, which had a significantly lower final contact angle than the other slopes $(p \leq$ $0.001)$. As for the total contact angle, it remained greater during the $0^{\circ}$ slope than all other slopes ( $p \leq 0.005$ ). Finally, the $2.7^{\circ}, 3.6^{\circ}, 4.8^{\circ}$, and $7.1^{\circ}$ slopes presented a similar total contact angle ( $p=0.14-0.24$ ) aside from the $2.7^{\circ}$ slope only, which was found to have a larger total contact angle than the $4.8^{\circ}$ slope $(p=0.01)$.

\section{Pushrim Kinetics}

\section{Total Force and Perceived Effort}

Figure 3(d)-(f) and Table 2 summarize the $\mathrm{F}_{\mathrm{TOT}}$ applied to the MWC pushrim with the nondominant UL during the push phase for the five different slopes. At first glance, the $\mathrm{F}_{\mathrm{TOT}}$ increased as the slope increased, except for the $\mathrm{F}_{\mathrm{TOT}}$ for the $2.7^{\circ}$ and $3.6^{\circ}$ slopes, where the curves overlap. This closeness is confirmed in the $\mathrm{F}_{\mathrm{TOT}}$ means $(p=0.03)$ and maxima $(p=0.02)$, which are similar between these two slopes (Figure 3(e)-(f)). There is also a similarity between the $\mathrm{F}_{\mathrm{TOT}}$ maxima for the $3.6^{\circ}$ and $4.8^{\circ}$ slopes $(p=0.01)$. The greatest mean $\mathrm{F}_{\mathrm{TOT}}$ difference was found between the $0^{\circ}$ and $2.7^{\circ}$ slopes compared with the differences observed between the other consecutive slopes. In comparison with the mean $\mathrm{F}_{\mathrm{TOT}}$ for the $0^{\circ}$ slope, the mean $\mathrm{F}_{\mathrm{TOT}}$ was greater from 37 to $80 \mathrm{~N}$ (93\%$201 \%, p<0.001$ ) and the maximum $\mathrm{F}_{\text {TOT }}$ was greater from 67 to $139 \mathrm{~N}(101 \%-210 \%, p<0.001)$ with an incline from the ground. Figure 4 summarizes the perceived efforts at the nondominant UL during propulsion on the different treadmill slopes, which match, to a certain extent, with the increase in the $\mathrm{F}_{\mathrm{TOT}}$ measured. However, the perceived efforts between the $2.7^{\circ}$ and $3.6^{\circ}$ slopes $(p=0.89)$ were similar.

\section{Tangential Component of Total Force}

Figure 3(g)-(i) and Table 2 summarize the $\mathrm{F}_{\mathrm{TANG}}$ calculated for the wheel on the nondominant side during the push phase for the different treadmill experimental tasks. As for the $\mathrm{F}_{\mathrm{TOT}}$, the $\mathrm{F}_{\mathrm{TANG}}$ increases in intensity with the slope, except for the similarity between the $2.7^{\circ}$ and $3.6^{\circ}$ slopes, a condition that was also found for the $\mathrm{F}_{\text {TANG }}$ means $(p=0.13)$ and maxima $(p=0.15)$ (Figure 3(h)-(i)). 

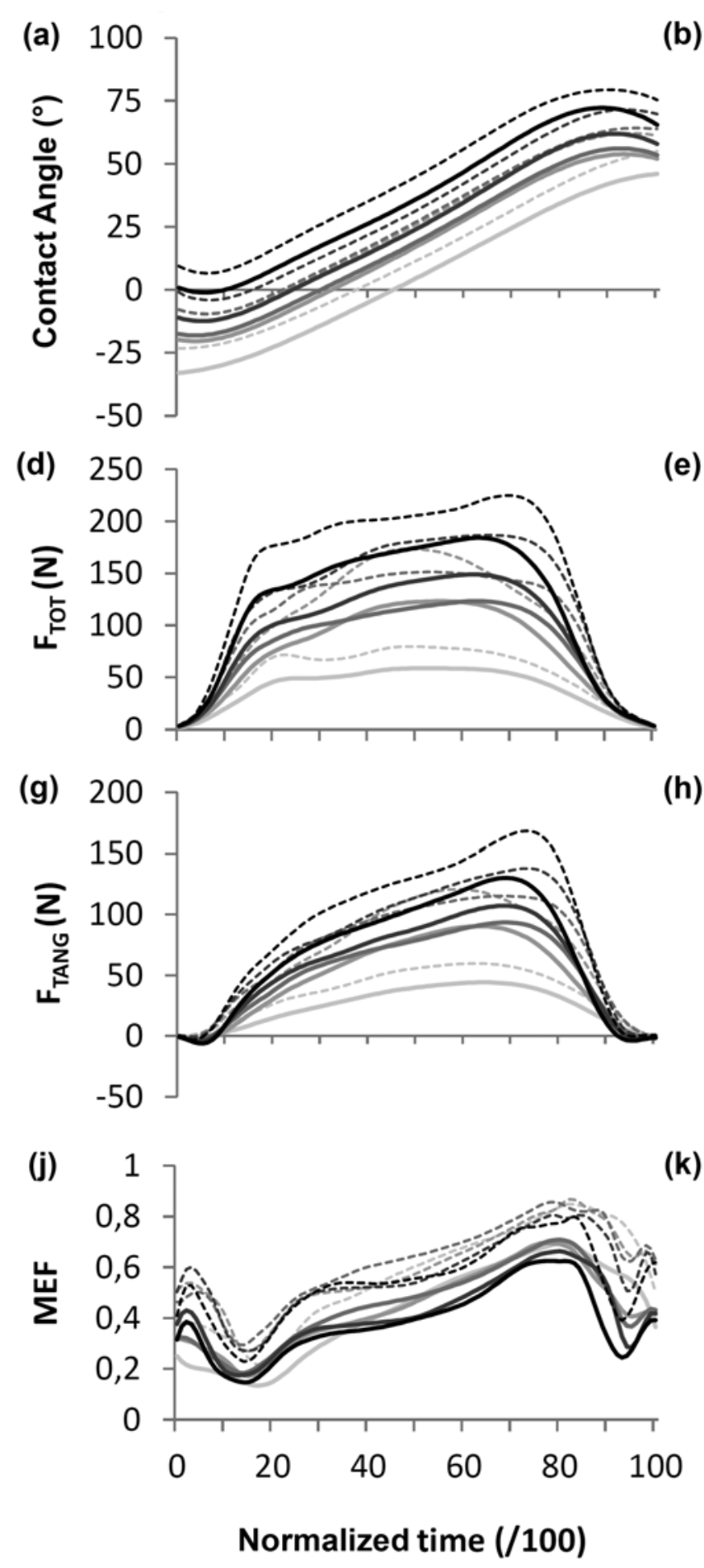

(b)

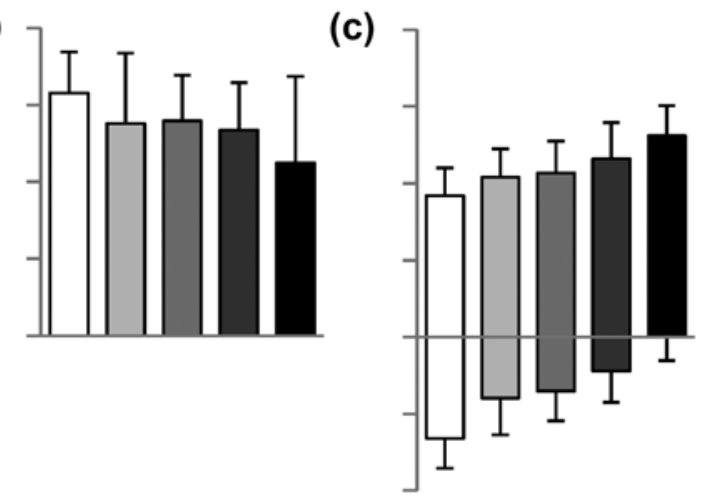

(e)

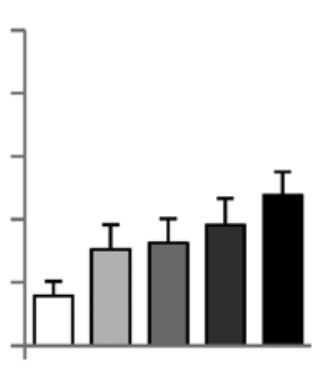

(h)

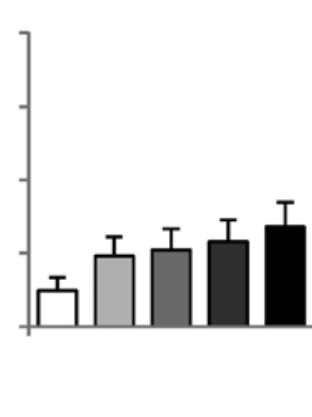

k)

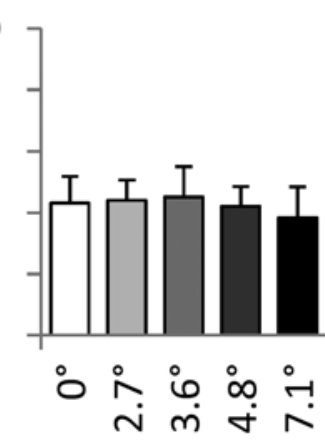

Mean (f)

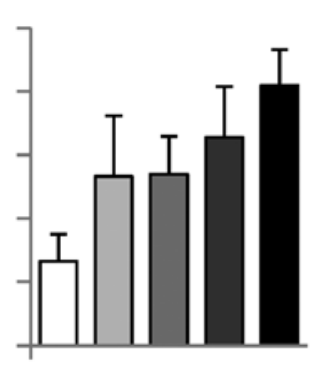

(i)

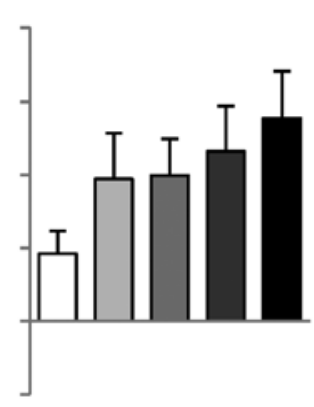

(I)

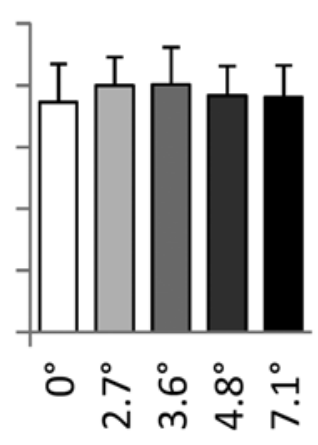

Peak

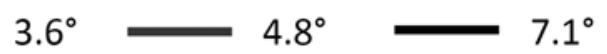

Figure 3.

Group time-normalized profile and mean and peak values (solid line) + standard deviation (dotted line) of (a)-(c) contact angle, (d)-(f) total force $\left(\mathrm{F}_{\mathrm{TOT}}\right),(\mathbf{g})-(\mathbf{i})$ tangential component of force $\left(\mathrm{F}_{\mathrm{TANG}}\right)$, and $\mathbf{( j )}$ - $(\mathbf{l})$ mechanical effective force (MEF) for five different slopes at constant speed $($ mean $=1.17 \pm 0.18 \mathrm{~m} / \mathrm{s})$. 


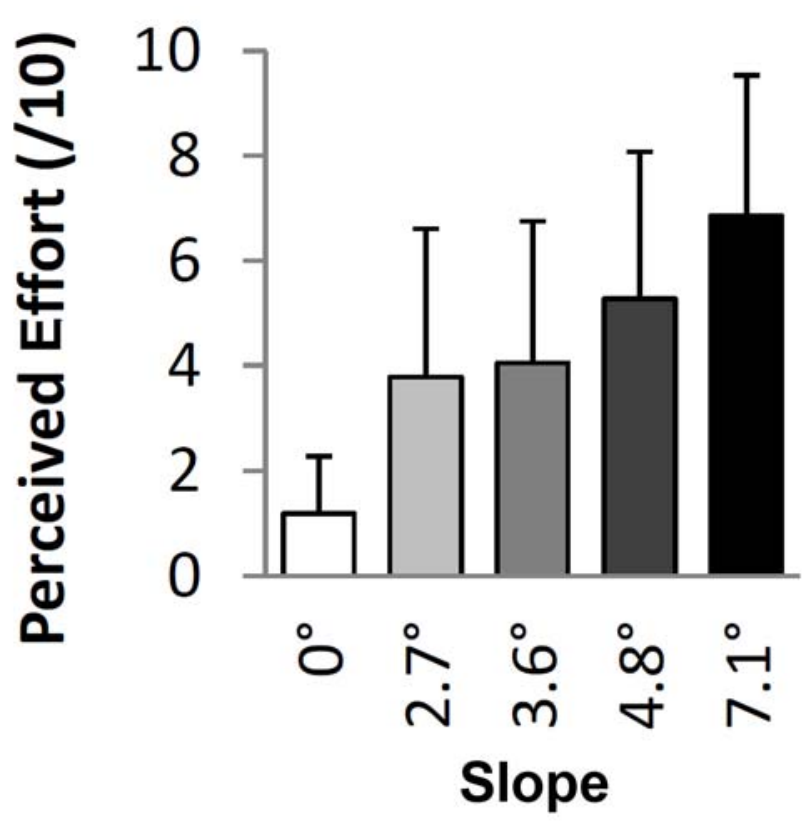

Figure 4.

Group means + standard deviation of perceived effort at nondominant upper limb rated using $10 \mathrm{~cm}$ visual analog scale after each task for five different slopes at constant speed (mean = $1.17 \pm 0.18 \mathrm{~m} / \mathrm{s})$.

Similarities between $\mathrm{F}_{\text {TANG }}$ means $(p=0.02)$ and maxima ( $p=0.01$ ) for the $3.6^{\circ}$ and $4.8^{\circ}$ slopes were also present, as well as between these same values obtained for the $4.8^{\circ}$ and $7.1^{\circ}$ slopes (mean: $p=0.08$, maximum: $p=0.01$ ). As for the mean $\mathrm{F}_{\mathrm{TANG}}$ the greatest difference was also found between the $0^{\circ}$ and the $2.7^{\circ}$ slopes compared with the differences observed between the other consecutive slopes. In comparison with the mean $\mathrm{F}_{\text {TANG }}$ at a $0^{\circ}$ slope, the mean $\mathrm{F}_{\text {TANG }}$ was greater from 24 to $44 \mathrm{~N}(96 \%-176 \%, p<0.001)$ and the maximum $\mathrm{F}_{\text {TANG }}$ was greater from 51 to $93 \mathrm{~N}$ (112\%$201 \%, p<0.001$ ) with an incline from the ground.

\section{Mechanical Effective Force}

Figure 3(j)-(l) and Table 2 show the MEF, measured for the nondominant side, for the different treadmill slopes. The MEF maxima, which are located around 80 percent of the propulsion phase (Figure 3(j)), were similar from one condition to the next $(p>0.05)$, with an average of $0.78 \pm 0.10$. For the mean MEF, all the values were similar ( $p>0.05$ ), averaging $0.42 \pm 0.08$.

\section{DISCUSSION}

\section{Shortened Recovery Phase}

The results of the present study clearly support the hypothesis that the duration of the recovery phase declined by approximately 70 percent, while the push phase remained similar, when the slope progressively increased from $0^{\circ}$ to $7.1^{\circ}$ and the treadmill speed stayed the same. These results are consistent with those of Van Der Woude et al. in a study involving athletes in an MWC on a treadmill at a steady speed and with slopes of $0^{\circ}, 1^{\circ}$, $2^{\circ}$, and $3^{\circ}[19]$. Furthermore, a study by Chow et al. done over ground with young men with paraplegia at a natural self-selected speed, which tended to decline by about 3 percent as the angle of the slope increased from $0^{\circ}$ to $6^{\circ}$, reported a similar behavior with the recovery phase declining by about 34 percent [17]. Thus, pushing frequency increases in order to offset the effect of gravitational force, which tends to pull the MWC downward and backward between strokes and intensifies as the slope increases. According to some studies, task execution frequency is linked to musculoskeletal disorders and pain in the shoulder and wrist [9]. Also, Boninger et al. [32] reported a direct correlation between an increase in pushing frequency and the risk of median nerve injury. Hence, UL risk exposure may increase as the slope augments.

\section{Forward Displacement and Shortened Contact Angle on Pushrim}

The initial and final contact angles (i.e., $-19.84^{\circ}$ and $52.04^{\circ}$, respectively, at an incline of $2.7^{\circ}$ and a mean speed of $1.17 \mathrm{~m} / \mathrm{s}$ ) reported in the current study coincide well with values previously reported by Veeger et al. [33]. They measured contact angles of $-20.1^{\circ}$ at the start of the push phase and $57.9^{\circ}$ at the end of the push phase among a group of five athletes performing treadmill propulsion at a speed of $1.11 \mathrm{~m} / \mathrm{s}$ with a $3^{\circ}$ slope. In the present study, when the slope progressively increased from $0^{\circ}$ to $7.1^{\circ}$ while the treadmill speed remained constant, the initial contact of the hand with the pushrim was found to move slightly forward, while the total contact angle was initially decreased and remained stable for slopes equal to or greater than $3.6^{\circ}$ thereafter. The forward displacement of the total contact angle documented in the present study is in agreement with the results previously reported by Chow et al. [17]. They reported that with an increase in the angle of the slope, there was an increase in the forward flexion of the trunk, which could partly explain the forward 
migration of the hand observed on the pushrim, as seen in the present study. However, contrary to our findings, they reported an increase of 4 percent in the total contact angle. This difference may be attributable to the declining propulsion speed allowed in their study as the slope increased, whereas the present study was performed at a constant speed. A study by Gil-Agudo et al. completed on a treadmill has also described a slight increase in the total contact angle possibly linked to an increase in treadmill speed from 0.83 to $1.11 \mathrm{~m} / \mathrm{s}$ [20]. On the other hand, Richter et al. showed that there was a decrease of 25 percent in the total contact angle and of speed (treadmill speed: 1.16 $\mathrm{m} / \mathrm{s}$ at $0^{\circ}$ and $0.43 \mathrm{~m} / \mathrm{s}$ at $6^{\circ}$ ) when the slope increased from $0^{\circ}$ to $6^{\circ}$ [12], which compares well to the findings in the present study ( $-28.9 \%$ between $0^{\circ}$ and $7.1^{\circ}$ slopes). However, Richter et al. the present study did allow participants to reduce the speed of the treadmill as the slope increased. Globally, the forward migration of the initial contact angle and the stable final contact angle that results in shortened total contact angles when the slope is introduced $\left(>0^{\circ}\right)$ may be attributable to forward trunk flexion, as suggested by Chow et al. [17]. However, the forward trunk flexion at the end of the push phase may be restricted by the strength-generating capability of the trunk muscles to work eccentrically during the push phase and concentrically during the recovery phase. The fact that some participants were also overweight with abdominal obesity may have limited their ability to forward flex their trunk during MWC propulsion, especially when the slope was steeper (e.g., $7.1^{\circ}$ slope). Alternatively, the reduced contact angle may also represent a strategy to accommodate for the substantially elevated forces and minimize UL fatigue and risk exposure.

\section{Increase in Pushrim Forces}

The results of the present study yield only partial support for the hypothesis suggesting that the $\mathrm{F}_{\mathrm{TOT}}$ and $\mathrm{F}_{\text {TANG }}$ applied at the pushrim would significantly rise as the slope increases during treadmill propulsion. Although the $\mathrm{F}_{\mathrm{TOT}}$ and $\mathrm{F}_{\mathrm{TANG}}$ generally rise as the slope increases, few similarities between slopes were revealed and were predominantly found between the $2.7^{\circ}$ and $3.6^{\circ}$ slopes. Nonetheless, when the slope progressively increased from $0^{\circ}$ to $7.1^{\circ}$ and the treadmill speed remained the same, the $\mathrm{F}_{\mathrm{TOT}}$ and its $\mathrm{F}_{\mathrm{TANG}}$ increased by just over 200 percent. Richter et al. reported a comparable increase between $0^{\circ}$ and $6^{\circ}$ slopes despite a reduced speed [12]. Also, the scales of perceived effort in the nondominant
UL corroborate this progressive and large increase in pushrim force as the slope increases. This substantial increase may explain why, for many participants, it only took a few strokes before the efforts were perceived as being elevated and a state of fatigue progressively set in during the experiment. For other participants, the magnitude of force required to propel as the slope increased eventually exceeded their capability to generate force with their ULs and prevented them from performing the more demanding slopes as evidenced by the success rate reported. These great forces confirm the need for rehabilitation professionals to propose UL-strengthening programs for individuals who use a MWC to reach a strength-generating capability strong enough to propel uphill (absolute strength [11]) while minimizing fatigue and risk exposure of UL secondary musculoskeletal impairments (relative strength). Alternatively, these last points of discussion reinforce the importance of building accessible access ramps that are not too steep (i.e., 1:20 or 1:16) to minimize these effects and optimize MWC accessibility. The fact that the force applied at the pushrim increased drastically between $0^{\circ}$ and $2.7^{\circ}$ slopes, but remained comparable between $2.7^{\circ}$ and $3.6^{\circ}$ slopes, suggests that the relationship between the slope and the force applied at the pushrim may not be linear. This should also be considered when developing assessment and training protocols for treadmill MWC propulsion in the future.

\section{Preservation of Mechanical Effective Force}

As for the hypothesis suggesting similar MEF across the different slopes tested, the results of the present study strongly support it. In fact, when the slope progressively increased from $0^{\circ}$ to $7.1^{\circ}$ and the treadmill speed stayed the same, the MEF remained statistically constant between 0.45 and 0.38 , with an observed tendency to decrease at the steepest slope. On the contrary, a study examining MEF in relation to MWC on a treadmill set at a constant speed of $0.9 \mathrm{~m} / \mathrm{s}$ reported MEFs of about 0.50 during propulsion with $0^{\circ}$ slope and an MEF of 0.55 when the slope rose to $3^{\circ}$ [13]. This represents a significant MEF increase of approximately 18 percent with the increase in the slope. The decreasing tendency reported in the present study may be attributable to the higher propulsion speed than in Yang et al. (i.e., 1.17 vs $0.9 \mathrm{~m} / \mathrm{s}$ ) [13]. In fact, Boninger et al. maintained that the MEF decreases with increasing speed [34]. The development of localized UL fatigue as the trials progressed may also have played a role in the decline of MEF reported despite 
the rest periods offered. However, the similarity in the data collected indicates that effective compensatory strategies were used to maintain the MEF despite the substantial increase in the angle of the slope.

\section{Implications for Clinical Practice, Research, and Society}

The results of this study show that pushing frequency and the forces that the ULs must generate substantially increase with a steeper slope at a constant speed. That is why it is crucial to build access ramps with smaller slopes to decrease the risk of UL injuries (i.e., reduced relative muscular demand). Slopes of 1:20 and 1:16, corresponding with inclines of $2.7^{\circ}$ and $3.6^{\circ}$, respectively, require similar efforts to climb and should therefore be favored rather than slopes of $1: 12$, representing a $4.8^{\circ}$ incline in new buildings. Also, other inclined surfaces in the natural environment, such as roads and sidewalk ramps, are not subject to standards that consider the specifics of MWC propulsion. Therefore, good UL muscle strength must be developed or maintained and be combined with a structured MWC skills training program to ensure access to various environments and foster greater autonomy and better social participation for MWUs. In addition, the development of a cardiorespiratory, strengthening, or task-specific training program on a treadmill, inspired by existing protocols used in gait training on a treadmill, may allow rehabilitation professionals to better address MWC propulsion training and optimize fitness among individuals who rely on an MWC for mobility.

\section{Study Limitations}

This study presents limitations that need to be considered when interpreting the results. The results should be interpreted with caution owing to the convenience sample including a relatively small number of participants $(n=18)$ and its potential effect on statistical power, although moderate to strong effect sizes can be computed based on the results presented in Figure 2. Additionally, the fact that participants were all well-experienced MWUs (range: 4.422.1 yr of experience) since the recruitment was restricted to MWUs with SCI living in the community and that the proportion of women in the sample of participants (5.6\%) was lower than found in the general population of individuals living with SCI (19.4\%) [35] may limit the possibility of generalizing the results of the present study for the entire population or specific subgroups of MWUs. The fact that all participants were tested with their own personal MWC and that their optimal MWC positioning and config- uration parameters may have differed across participants (e.g., horizontal and vertical rear axle positions relative to the shoulder joint position, seat tilt, backrest angle) also need to be considered when interpreting the present results and will warrant additional attention in future studies. Selecting a unique self-selected natural treadmill speed used across all slopes by each participant made it possible to compare intrasubject data. However, some of them found this demanding: while 88.9 percent managed to propel the MWC up a $3.6^{\circ}$ slope, and 77.8 percent up a $4.8^{\circ}$ slope, only 55.6 percent of the participants successfully propelled their MWC up a slope of $7.1^{\circ}$. Some studies have identified freely chosen propulsion speeds, which declined as the angle increased and resulted in slightly higher success rates than the ones found in the present study [5,12,17]. However, although imposing a constant propulsion speed lessens the similarity with some other studies, the constant speed used in the present study made it possible to isolate the effects of this variable. In addition, a few of the participants mentioned that cardiorespiratory fatigue was a limitation in completing the experimental tasks. Therefore, for research and clinical purposes, it would be useful to study cardiorespiratory demands to better define the requirements for MWC propulsion on an inclined surface at different angles on a motorized treadmill. Lastly, the fact that only pushrim kinetics were analyzed restricts our ability to fully understand the UL loading and efforts during the manual wheelchair propulsion on a motorized treadmill and warrants comprehensive biomechanical studies (e.g., UL joint moments, electromyography of UL muscles) in the future.

\section{CONCLUSIONS}

In this study, we quantified the movement strategies and forces applied to the pushrim on the nondominant side during MWC propulsion on a treadmill with different slopes. The results reveal that as the slope of the treadmill increases, the duration of the recovery phase generally decreases, whereas the duration of the push phase and the total contact angle, which is displaced forward, remain constant. The results also show that the forces applied at the pushrim, particularly the $\mathrm{F}_{\mathrm{TOT}}$, generally increase while the MEF remains constant. Many similarities (i.e., duration of recovery phase, $\mathrm{F}_{\mathrm{TOT}}$, $\mathrm{F}_{\mathrm{TANG}}$ perceived exertion) were found between the $2.7^{\circ}$ and $3.6^{\circ}$ slopes during MWC propulsion on a treadmill. 
Future studies incorporating UL kinematics, kinetics, and electromyographic analysis could definitively strengthen the results of the present study and provide additional evidence-based knowledge that may influence the way this MWC skill is taught and being trained among individuals with SCI or other MWUs in clinical practice.

\section{ACKNOWLEDGMENTS}

\section{Author Contributions:}

Study concept, design, and supervision: D. H. Gagnon.

Acquisition of data: A. Babineau, A. Champagne, G. Desroches, D. H. Gagnon.

Analysis and interpretation of data: A. Babineau, A. Champagne, G. Desroches, D. H. Gagnon.

Statistical analysis: D. H. Gagnon.

Drafting of manuscript: D. H. Gagnon, A. Babineau.

Critical revision of manuscript for important intellectual content:

D. H. Gagnon, R. Aissaoui, G. Desroches, A. Champagne.

Obtained funding: D. H. Gagnon.

Administrative, technical, or material support: G. Desroches, D. H. Gagnon

Financial Disclosures: The authors have declared that no competing interests exist.

Funding/Support: This material was based on work supported by the Fonds de la Recherche du Québec-Santé (FRQS). The equipment and material required for the research completed at the Pathokinesiology Laboratory was financed by the Canada Foundation for Innovation. Dr. Gagnon holds a Junior 1 Research Career Award from the FRQS. Ms. Champagne was supported by a summer research studentship financed by the Quebec Rehabilitation Research Network (REPAR). Dr. Desroches is supported by a postdoctoral fellowship from the Canadian Institutes of Health Research (CIHR) in collaboration with the March of Dimes of Canada. Drs. Gagnon and Aissaoui are members of the Multidisciplinary SensoriMotor Rehabilitation Research Team supported by the CIHR and the Quebec-Ontario Spinal Cord Injury Mobility Research Group funded by the REPAR and the Ontario NeuroTrauma Foundation.

Additional Contributions: The authors would like to thank Michel Goyette (engineer), Daniel Marineau (technician), Youssef El Khamlichi (research associate), and Philippe Gourdou (research associate) for their contributions to this project.

Institutional Review: All the participants were informed of the objectives and nature of the study, which was approved by the Research Ethics Committee of the Centre for Interdisciplinary Research in Rehabilitation of Greater Montreal (\#715-0312). Participants gave their written consent before starting the study.

Participant Follow-Up: The authors do not plan to inform participants of the publication of this study. However, participants have been encouraged to check the study Web site for updated publications.

\section{REFERENCES}

1. Canada Mortgage and Housing Corporation. Measuring the effort needed to climb access ramps in a manual wheelchair [Internet]. Ottawa (Canada): Canada Mortgage and Housing Corporation; 2003 [cited 2013 Jun 18]. Available from: http://www.cmhc.ca/en/inpr/rehi/rehi_017.cfm

2. Gouvernement du Québec. Régie du bâtiment du Québec (RBQ). Normes de conception sans obstacles: Guide d'utilisation. [Standards for barrier-free design: User's guide]. Sect. 3.8.3.4. Quebec City (Canada): Gouvernement du Québec; 2010. French.

3. Gouvernement du Québec, Régie du bâtiment du Québec (RBQ). Construction code, building act. Chap. 1, Sect. III, 10.3.8.4. Architectural and Transportation Barriers Compliance Board. Quebec City (Canada): Gouvernement du Québec; 2013. French.

4. Architectural and Transportation Barriers Compliance Board. Americans with Disabilities Act accessibility guidelines for buildings and facilities (ADAAG). Washington (DC): U.S. Access Board; 1998.

5. Sanford JA, Story MF, Jones ML. An analysis of the effects of ramp slope on people with mobility impairments. Assist Technol. 1997;9(1):22-33. [PMID:10168021] http://dx.doi.org/10.1080/10400435.1997.10132293

6. Templer JA, Wineman J, Zimring CM. Guidelines for accommodating the handicapped on crossings: Final report. Washington (DC): Department of Transportation, Federal Highway Administration; 1984.

7. Sweeney GM, Clark AK, Harrison RA, Bulstrode SJ. An evaluation of portable ramps. Br J Occup Ther. 1989; 52(12):473-75.

8. Steinfeld E, Schroeder S, Bishop M. Accessible buildings for people with walking and reaching limitations. Washington (DC): U.S. Department of Housing and Urban Development; 1979.

9. Paralyzed Veterans of America Consortium for Spinal Cord Medicine. Preservation of upper limb function following spinal cord injury: A clinical practice guideline for healthcare professionals. J Spinal Cord Med. 2005;28(5):434-70. [PMID:16869091]

10. Boninger ML, Koontz AM, Sisto SA, Dyson-Hudson TA, Chang M, Price R, Cooper RA. Pushrim biomechanics and injury prevention in spinal cord injury: Recommendations based on CULP-SCI investigations. J Rehabil Res Dev. 2005;42(3 Suppl 1):9-19. [PMID:16195959]

11. Arabi H, Aissaoui R, Rousseau J, Bourbonnais D, Dansereau J. Evaluation of minimal mechanical effort during the ramp access of manual wheelchair. Ergonomia IJE\&HF. 2004;26(3):253-59.

12. Richter WM, Rodriguez R, Woods KR, Axelson PW. Stroke pattern and handrim biomechanics for level and 
uphill wheelchair propulsion at self-selected speeds. Arch Phys Med Rehabil. 2007;88(1):81-87. [PMID:17207680] http://dx.doi.org/10.1016/j.apmr.2006.09.017

13. Yang YS, Koontz AM, Yeh SJ, Chang JJ. Effect of backrest height on wheelchair propulsion biomechanics for level and uphill conditions. Arch Phys Med Rehabil. 2012;93(4): 654-59. [PMID:22325682]

http://dx.doi.org/10.1016/j.apmr.2011.10.023

14. van der Woude LH, Veeger HE, Dallmeijer AJ, Janssen TW, Rozendaal LA. Biomechanics and physiology in active manual wheelchair propulsion. Med Eng Phys. 2001;23(10):713-33. [PMID:11801413] http://dx.doi.org/10.1016/S1350-4533(01)00083-2

15. Sabick MB, Kotajarvi BR, An KN. A new method to quantify demand on the upper extremity during manual wheelchair propulsion. Arch Phys Med Rehabil. 2004;85(7): 1151-59. [PMID:15241767] http://dx.doi.org/10.1016/j.apmr.2003.10.024

16. Kulig K, Rao SS, Mulroy SJ, Newsam CJ, Gronley JK, Bontrager EL, Perry J. Shoulder joint kinetics during the push phase of wheelchair propulsion. Clin Orthop Relat Res. 1998;(354):132-43. [PMID:9755772]

17. Chow JW, Millikan TA, Carlton LG, Chae WS, Lim YT, Morse MI. Kinematic and electromyographic analysis of wheelchair propulsion on ramps of different slopes for young men with paraplegia. Arch Phys Med Rehabil. 2009; 90(2):271-78. [PMID:19236980]

http://dx.doi.org/10.1016/j.apmr.2008.07.019

18. Westerhoff P, Graichen F, Bender A, Halder A, Beier A, Rohlmann A, Bergmann G. Measurement of shoulder joint loads during wheelchair propulsion measured in vivo. Clin Biomech (Bristol, Avon). 2011;26(10):982-89.

[PMID:21719168]

http://dx.doi.org/10.1016/j.clinbiomech.2011.05.017

19. Van Der Woude LH, Hendrich KM, Veeger HE, van Ingen Schenau GJ, Rozendal RH, de Groot G, Hollander AP. Manual wheelchair propulsion: Effects of power output on physiology and technique. Med Sci Sports Exerc. 1988; 20(1):70-78. [PMID:2963939] http://dx.doi.org/10.1249/00005768-198802000-00011

20. Gil-Agudo A, Del Ama-Espinosa A, Pérez-Rizo E, PérezNombela S, Crespo-Ruiz B. Shoulder joint kinetics during wheelchair propulsion on a treadmill at two different speeds in spinal cord injury patients. Spinal Cord. 2010; 48(4):290-96. [PMID:19773798]

http://dx.doi.org/10.1038/sc.2009.126

21. Kwarciak AM, Turner JT, Guo L, Richter WM. Comparing handrim biomechanics for treadmill and overground wheelchair propulsion. Spinal Cord. 2011;49(3):457-62. [PMID:21042332] http://dx.doi.org/10.1038/sc.2010.149
22. Kirshblum SC, Burns SP, Biering-Sorensen F, Donovan W, Graves DE, Jha A, Johansen M, Jones L, Krassioukov A, Mulcahey MJ, Schmidt-Read M, Waring W. International standards for neurological classification of spinal cord injury (revised 2011). J Spinal Cord Med. 2011;34(6):535-46.

[PMID:22330108] http://dx.doi.org/10.1179/204577211X13207446293695

23. Curtis KA, Roach KE, Applegate EB, Amar T, Benbow CS, Genecco TD, Gualano J. Development of the Wheelchair User's Shoulder Pain Index (WUSPI). Paraplegia. 1995;33(5):290-93. [PMID:7630657] http://dx.doi.org/10.1038/sc.1995.65

24. Curtis KA, Roach KE, Applegate EB, Amar T, Benbow CS, Genecco TD, Gualano J. Reliability and validity of the Wheelchair User's Shoulder Pain Index (WUSPI). Paraplegia. 1995;33(10):595-601. [PMID:8848314] http://dx.doi.org/10.1038/sc.1995.126

25. Chapman LJ, Chapman JP. The measurement of handedness. Brain Cogn. 1987;6(2):175-83. [PMID:3593557] http://dx.doi.org/10.1016/0278-2626(87)90118-7

26. Cooper RA. SMARTWheel: From concept to clinical practice. Prosthet Orthot Int. 2009;33(3):198-209. [PMID:19658010] http://dx.doi.org/10.1080/03093640903082126

27. Kwarciak AM, Sisto SA, Yarossi M, Price R, Komaroff E, Boninger ML. Redefining the manual wheelchair stroke cycle: Identification and impact of nonpropulsive pushrim contact. Arch Phys Med Rehabil. 2009;90(1):20-26. [PMID:19154825] http://dx.doi.org/10.1016/j.apmr.2008.07.013

28. Hurd WJ, Morrow MM, Kaufman KR, An KN. Biomechanic evaluation of upper-extremity symmetry during manual wheelchair propulsion over varied terrain. Arch Phys Med Rehabil. 2008;89(10):1996-2002. [PMID:18929029] http://dx.doi.org/10.1016/j.apmr.2008.03.020

29. Desroches G, Aissaoui R, Bourbonnais D. Effect of system tilt and seat-to-backrest angles on load sustained by shoulder during wheelchair propulsion. J Rehabil Res Dev. 2006;43(7):871-82. [PMID:17436173] http://dx.doi.org/10.1682/JRRD.2005.12.0178

30. Cooper RA, Robertson RN, VanSickle DP, Boninger ML, Shimada SD. Methods for determining three-dimensional wheelchair pushrim forces and moments: A technical note. J Rehabil Res Dev. 1997;34(2):162-70. [PMID:9108343]

31. Lalumiere M, Gagnon DH, Hassan J, Desroches G, Zory R, Pradon D. Ascending curbs of progressively higher height increases forward trunk flexion along with upper extremity mechanical and muscular demands in manual wheelchair users with a spinal cord injury. J Electromyogr Kinesiol. 2013;23(6):1434-45. [PMID:23866992] http://dx.doi.org/10.1016/j.jelekin.2013.06.009 
32. Boninger ML, Cooper RA, Baldwin MA, Shimada SD, Koontz A. Wheelchair pushrim kinetics: Body weight and median nerve function. Arch Phys Med Rehabil. 1999;80(8):910-15. [PMID:10453767] http://dx.doi.org/10.1016/S0003-9993(99)90082-5

33. Veeger HE, van der Woude LH, Rozendal RH. Wheelchair propulsion technique at different speeds. Scand J Rehabil Med. 1989;21(4):197-203. [PMID:2631194]

34. Boninger ML, Souza AL, Cooper RA, Fitzgerald SG, Koontz AM, Fay BT. Propulsion patterns and pushrim biomechanics in manual wheelchair propulsion. Arch Phys Med Rehabil. 2002;83(5):718-23. [PMID:11994814] http://dx.doi.org/10.1053/apmr.2002.32455

35. National Spinal Cord Injury Statistical Center. Spinal cord injury facts and figures at a glance. J Spinal Cord Med. 2012;35(6):480-81. [PMID:23318031] http://dx.doi.org/10.1179/1079026812Z.000000000124
Submitted for publication July 23, 2013. Accepted in revised form January 8, 2014.

This article and any supplementary material should be cited as follows:

Gagnon DH, Babineau A, Champagne A, Desroches G, Aissaoui R. Pushrim biomechanical changes with progressive increases in slope during motorized treadmill manual wheelchair propulsion in individuals with spinal cord injury. J Rehabil Res Dev. 2014;51(5):789-802. http://dx.doi.org/10.1682/JRRD.2013.07.0168

\begin{tabular}{|c|c|}
\hline $\begin{array}{l}\text { AL subussions scregned Br } \\
\text { iThenticate }\end{array}$ & HEMBER \\
\hline 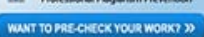 & $\begin{array}{l}\text { CROSSREF.ORG } \\
\text { THE CITATION LHKKIHG BACKEONE }\end{array}$ \\
\hline
\end{tabular}

